\title{
Human Immune Deficiency Virus Serostatus and Associated Factors Among Children of Adult Index Cases in Northern Ethiopia
}

\author{
Medhin Mehari $\mathbb{D}^{\prime}$ \\ Meresa Gebremedhin \\ Weldu (D) $^{2}$ \\ Teklit Angesom (iD) ${ }^{2}$ \\ Hagos Degefa Hidru (iD) \\ Hirut Teame $\left.{ }^{\prime}\right)^{\prime}$ \\ Haftay Gebremedhin (ID) \\ Yonas Angaw $\mathbb{D}^{\prime}$ \\ Embay Amare Alemseged (D) \\ 'Adigrat University College of Medicine \\ and Health Science, Department of Public \\ Health, Adigrat, Tigrai, Ethiopia; ${ }^{2}$ Aksum \\ University College of Medicine and \\ Health Science, Department of Public \\ Health, Aksum, Tigrai, Ethiopia
}

\begin{abstract}
Introduction: Children whose parents with human immunodeficiency virus (HIV) and family of index clients are at high risk of HIV infection. Family testing is an efficient and effective way of identifying children's HIV. The number of children becoming newly infected with HIV remains unacceptably high. This study is to assess human immune deficiency, virus serostatus, and associated factors among children of adult index cases in central Tigrai, Northern Ethiopia, 2019.
\end{abstract}

Methods: An institution-based cross-sectional study design was conducted to select a total of 454 index cases from February 01 to April 30, 2019. Data were collected from adult clients on antiretroviral treatment who have children using administered questionnaires and data extraction from the hospital antiretroviral register. Simple random sampling was used to select the index cases using the medical record number. Binary logistic regression analysis, odds ratio, and $95 \%$ confidence interval were used to determine the strength of association between dependent and independent variables. Statistical significance was declared a P-value $<0.05$.

Results: The prevalence of HIV in children from family index case testing was $8.9 \%$ with 95\% CI (6.5-11.6). Female index clients [AOR=0.18, 95\% CI: 06-0.55], the age of the child $[\mathrm{AOR}=0.86,95 \% \mathrm{CI}: 0.76,0.97]$, importance of $\mathrm{HIV}$ testing $[\mathrm{AOR}=5.20,95 \% \mathrm{CI}$ : 2.2011.96], and discussion HIV testing [AOR=3.22, 95\% CI: $1.5-16.84$ ]. Participants who did not discuss HIV were 3.2 more likely have HIV positive child than who discussed with family members.

Conclusion: The majority of the index clients test their children, but the prevalence rate of HIV in children from family index case testing is high. Strategies should be developed on how to communicate with household members about HIV.

Keywords: HIV serostatus, human immunodeficiency virus, HIV index case, HIV in children, antiretroviral therapy, ART, HIV/AIDS

\section{Introduction}

Index case testing refers to HIV Testing and Counseling (HTC) service providers giving counseling for people diagnosed with HIV and offering HTC to their children and other family members. ${ }^{1}$ Index case finding is very important to improve Antiretroviral Therapy (ART) coverage in children and novel approaches to identifying and linking the children to care. ${ }^{2}$

Family testing is an efficient and effective way of identifying children with HIV. $^{3}$ A family-centered approach has the potential to increase the focus on pediatric testing and treatment. ${ }^{4}$
Correspondence: Medhin Mehari Tel +251914194266

Email medhinmehari493@gmail.com 
Globally, the annual number of new infections among children [0-14 years] has almost halved since 2010 with a $47 \%$ reduction in new HIV cases. Lack of investment, resources, and research to optimize pediatric testing and to increase pediatric antiretroviral (ARV) medicines means children are in danger of being behind. ${ }^{5}$

In sub-Saharan Africa, extreme poverty and experiencing a burden of illness and disease are affecting many children disproportionately. The emergence of HIV/ Acquired immune deficiency syndrome (AIDS) has exacerbated long-standing challenges to improving children's health in the region. ${ }^{6}$ Mortality is very high among children whose parents are infected with HIV. ${ }^{7}$

Currently, in Ethiopia, 738,976 people living with HIV; however, only 23,400 children under the age of 15 are taking Antiretroviral (ARV). Based on the 2010-2014 strategic plan, ART coverage remains low for children [age $<15$ ] living with HIV. ${ }^{8}$

Parents should support disclosing their children to ease their children's involvement in treatment and adherence. Children should also be offered counseling and other psychosocial support. ${ }^{3}$ Even, in the presence of continued progress in the prevention of HIV transmission, the World Health Organization (WHO) and United Nations Children's Emergency Fund (UNICEF) project that 1.9 million children will need HIV treatment in $2020 .{ }^{9}$

Children of the family of index clients are at high risk of HIV infection. Testing for HIV and linking to care for those identified by the families of the index cases will improve the health outcomes of the children. ${ }^{10}$ Familycentered approaches to HIV prevention and care present an important direction for preventing pediatric infections while improving overall family health. ${ }^{11}$

Without treatment, most children infected with HIV will die when they are 5 years. ${ }^{12}$ Thus, it is critically important to find children exposed to HIV and make ensure these children receive HIV testing and treatment. ${ }^{13}$ The index-patient model allows detection of HIV-positive children and efficiently linking them to treatment and care. ${ }^{14}$ In 2017, 180, 000 children became infected with HIV, far from the 2018 target of eliminating new HIV infections among children. Even though the overall HIV treatment level is high, there is a large injustice being committed against our children. ${ }^{15}$

There is a large population of children living with HIV in Ethiopiawho have not been diagnosed. Most HIVinfected children are diagnosed very late. ${ }^{16}$ Moreover, many older children living with HIV are long-term survivors who have not been previously identified as HIV-infected. Other testing strategies are needed to ensure that $100 \%$ of HIV-exposed children are identified. ${ }^{17}$

There is no clear research about serostatus and associated factors of HIV among children of an index family in Ethiopia. This study aims to assess HIV serostatus and associated factors among children of adult index cases in central Tigrai, Northern Ethiopia.

\section{Methods and Materials}

\section{Study Area and Period}

The study was conducted in the central zone of Tigrai at general Hospitals (Adwa Hospital, St Mary Hospital, and Abyi-adi Hospital). The total number of children identified from the family index at the hospitals was 1646 and the children on ART in the three hospitals was 104. Amongst 1272 index cases, those having children were 536, 607, and 129 in Adwa, Aksum, and Abyi-adi Hospital, respectively. The study was conducted from February 01 to April 30, 2019.

\section{Study Design}

An institution-based cross-sectional study was employed to assess human immune deficiency, virus serostatus, and associated factors among children of adult index cases.

\section{Inclusion and Exclusion Criteria} Inclusion

ART clinic attendants whose age is greater than 18 , registered in the family index registration, have children $<15$ years, and their children's HIV status was known.

\section{Exclusion}

Those who have to follow up but, with mental illness, unable to hear and speak, those whose partner is already included in the study and their children's HIV status was not known.

\section{Operational Definitions}

Children: Individuals aged less than 15 years.

Family members: people living in the household, children, and other members connected either biologically or by choice.

Index case: first documented patient (in a family) diagnosed with HIV and attending a chronic continuum of care and support services in health facilities.

Index case testing: HTC service providers giving counseling for people diagnosed with HIV and offering HIV 
counseling and testing to their children and other family members.

\section{Sample Size Determination}

A sample size of 239 was calculated for the first objective using a single population proportion formula considering $18 \%,{ }^{17}$ the prevalence of HIV among children of an index case, $95 \%$ level of confidence, $5 \%$ precision level, and $5 \%$ for non-response rate. Considering the second objective, double population proportion formula was used to calculate a total sample of 454 index cases by taking $95 \% \mathrm{CI}$, OR (2.1), power $(80 \%)$, the previous studies outcome among non-exposed (34\%), the proportion among exposed $(62 \%)$, and adding $5 \%$ none response rate. We took the largest sample and the final sample size was 454 .

\section{Sampling Technique and Sampling Procedure}

The sample size was proportionally allocated to each of the three hospitals, according to the expected size of index cases. Then, a simple random sampling method (random number generator) was employed among those found eligible from the family index register. Interview and secondary data reviews were conducted to assess the risk factors for the serostatus of children in the family (Figure 1)

\section{Data Collection Procedure}

The data were collected from adult index cases from the register, card review, and an interviewer-administered, locally translated [Tigrigna] questionnaire. The questionnaire was adopted from different evidence to assess risk factors of HIV serostatus in children. Six data collectors, who work at the ART Clinic in the same health institutions, were recruited. From a total of 3,309 patients enrolled in HIV care services in the three hospitals, 1272 were screened for eligibility from Family Index Testing (FIT) register. Of this total population, 454 adult index patients who have at least one child were selected using medical record numbers by a simple random sampling method. One child was selected for checking serostatus by lottery method in instances where an indexing client had more than one child. The data were collected during the client's follow-up and for a coffee ceremony.

\section{Data Quality Control}

Pre-testing was done and data collectors with their supervisors were given two days of training on the aim of the study and data collection process. The questionnaire was initially prepared in English, translated to the local language (Tigrigna), and back to English to check its consistency.

Questionnaires' completeness, accuracy, clarity, and consistency were checked by the supervisors and the principal investigators. Completeness and consistency of variables during data entry and analysis were checked.

\section{Data Management and Analysis}

After all the relevant data were collected, a final check of completed questionnaires was conducted before data entry. Data were coded, checked, and entered using Epi-Info and exported to SPSS for analysis. Descriptive statistics and cross-tabulation were used to describe the study population. Binary logistic regression was used to assess the degree of association between dependent and independent variables. The odds ratio with the $95 \%$ confidence interval was used to measure the strength of association. Those variables

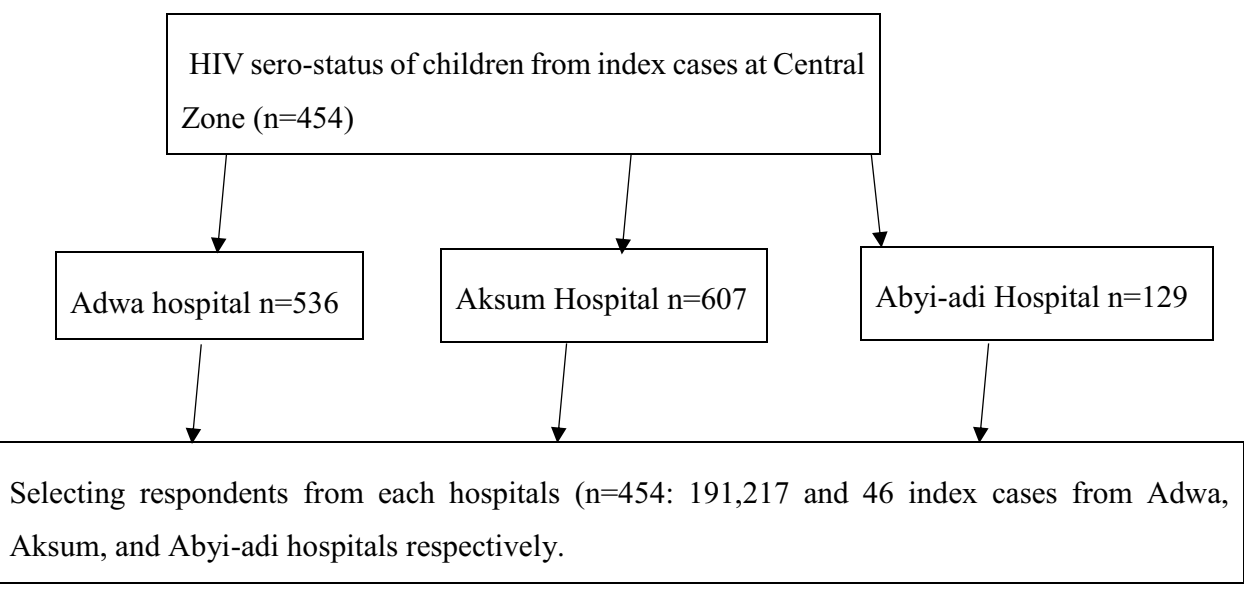

Figure I Schematic representation of the sampling technique and procedure in central zone, Tigrai, Northern Ethiopia, 2019. 
associated with bivariate logistic regression with a significance level of $p$-value $<0.05$ were entered into a multivariate logistic regression model to find the important determinants by controlling possible confounding effects. Finally, statistical significance was declared at $\mathrm{P}$-value $<0.05$.

\section{Results}

\section{Socio-Demographic Characteristics of the Participants}

The response rate was $98.9 \%$. Of the respondents, $70 \%$ were female, Orthodox Christians (95.8\%), ethnically Tigaru (99.1\%), and over $80 \%$ were urban dwellers. While the majority were married $(66.8 \%)$, nearly onethird had never attended or completed formal education.

The mean age of children identified through the index case testing was 9.48 years and $53.5 \%$ were female (Table 1). These 449 patients were focal in the identification of 1176 family members at risk of HIV (3.6 family members identified per index patient). Including 869 (74\%) children and 307 (26\%) partners and other family members.

\section{Health Status of Participants}

Out of participants 499 (100\%) were on ART, 327 (72.8\%) having started ART within a year. A total of 242 (53.9\%) participants have recent CD4 counts greater than 350 and $249(55.5 \%)$ were currently in WHO Stage I. A total of $430(95.8 \%)$ participants were in good condition and able to perform any type of work.

\section{Results Related to HIV Testing, Disclosure, and Discussion with Index Family Member}

Out of the total participants, $447(99.6 \%)$ stated both that HIV can only be identified by getting tested and that HIV can be prevented. However, through the family index

Table I Socio-Demographic Characteristics of Index Cases in Central Tigrai, Northern Ethiopia $(\mathrm{N}=449)$

\begin{tabular}{|c|c|c|c|}
\hline Characteristics & & Frequency & Percent \\
\hline \multirow[t]{2}{*}{ Sex } & Male & 139 & 31.0 \\
\hline & Female & 310 & 69.0 \\
\hline \multirow[t]{2}{*}{ Residence } & Urban & 361 & 80.4 \\
\hline & Rural & 88 & 19.6 \\
\hline \multirow[t]{4}{*}{ Marital status of participants } & Married & 300 & 66.8 \\
\hline & Divorced & 67 & 14.9 \\
\hline & Separated & 49 & 10.9 \\
\hline & Widowed & 31 & 6.9 \\
\hline \multirow[t]{5}{*}{ Educational status } & Illiterate & 48 & 10.7 \\
\hline & Read and write & 89 & 19.8 \\
\hline & Elementary education & 173 & 38.5 \\
\hline & High School Education & 113 & 25.2 \\
\hline & Diploma and above & 26 & 5.8 \\
\hline \multirow[t]{2}{*}{ Religion } & Orthodox & 430 & 95.8 \\
\hline & Muslim & 19 & 4.2 \\
\hline \multirow[t]{4}{*}{ Occupation } & Jobless & 63 & 14.0 \\
\hline & Merchant & 64 & 14.3 \\
\hline & Government employed & 69 & 15.4 \\
\hline & Private employed & 253 & 56.3 \\
\hline \multirow[t]{4}{*}{ Age index case } & $18-29$ & 48 & 10.7 \\
\hline & $30-39$ & 266 & 59.2 \\
\hline & $40-49$ & 117 & 26.1 \\
\hline & $>49$ & 18 & 4.0 \\
\hline \multirow[t]{2}{*}{ Sex of children } & Male & 209 & 46.5 \\
\hline & Female & 240 & 53.5 \\
\hline
\end{tabular}


Table 2 Results Related to HIV Testing and Disclosure to Families of Index Cases in Central Zone, Tigrai, Northern Ethiopia (N = 449)

\begin{tabular}{|c|c|c|c|}
\hline \multicolumn{2}{|l|}{ Characteristics } & \multirow{3}{*}{$\begin{array}{c}\text { Frequency } \\
42 \\
407\end{array}$} & \multirow{3}{*}{$\begin{array}{c}\text { Percent } \\
9.4 \\
90.6\end{array}$} \\
\hline Information about HTC service provision to children & Friends Mass media & & \\
\hline & Health workers & & \\
\hline \multirow[t]{2}{*}{ Initiated your children for HIV testing \& counseling } & Yes & 427 & 95 \\
\hline & No & 22 & 4.9 \\
\hline \multirow[t]{3}{*}{ Reason to start HIV testing to your children } & Prevent transmission & 283 & 63.0 \\
\hline & Told by HW & 147 & 32.7 \\
\hline & To know the status & 14 & 3.1 \\
\hline \multirow[t]{3}{*}{ Frequency your children get testing for HIV } & Every three month & 166 & 37.0 \\
\hline & Every six month & 50 & II.I \\
\hline & Every year & 231 & 51.4 \\
\hline \multirow[t]{2}{*}{ Disclose HIV status to adult household members } & Yes & 232 & 51.7 \\
\hline & No & 217 & 48.3 \\
\hline \multirow[t]{2}{*}{ Discussion about HIV with the adult family member } & Yes & 84 & 18.79 \\
\hline & No & 365 & 81.3 \\
\hline
\end{tabular}

Abbreviations: HW, health worker; HTC, HIV testing and counseling.

interview, 205 (45.7\%) said that partners can have different HIV test results, but 117 (26.1\%) said that partners will have the same HIV status.

Although over $95 \%$ of the index clients have initiated HIV testing with their children, their primary reasons for doing so showed that about one-third did so on the advice of health care workers only. Almost all the participants, $99.8 \%$ of the adult index prefer government health institutions for HIV testing of their families. Disclosure of one's HIV status to family members was below $50 \%$ and only $19 \%$ have discussed HIV with their families. During the interviews, the major reason $(151,69.6 \%)$ for nondisclosure included fear of stigma and discrimination (Table 2).

\section{Testing Yield and Outcomes of Children by HIV Testing}

There were 449 children found from family-based HIV testing and all were tested for HIV, with $8.9 \%$ [95\% CI, $6.5-11.6]$ children testing positive. Of the positive children, 21[52.5\%] were female and their mean age, when diagnosed as HIV positive, was 3.88. From positive children, $40[100 \%]$ were enrolled in HIV care and started ART treatment [Figure 2].

\section{Associated Factors for Serostatus of HIV in Children from Family-Based Testing}

The Association of independent variables with the outcome variable was analyzed based on bivariate logistic regression. Sex of index case, clinical WHO stage, occupation, age of a child, knowledge on the importance of HIV testing, reasons to initiate HIV testing, and discussion with family members about testing were found to have a significant association with the outcome variable. Adjusted Odds Ratio was calculated after these variables were entered into the multivariable logistic regression model.

Multivariable analysis found four variables (sex, age, knowledge on the importance of HIV testing, and discussion about HIV testing of the adult index case) had a significant association with the outcome variable. Female index clients were less likely to have HIV-positive children than male index participants $[\mathrm{AOR}=0.18,95 \% \mathrm{CI}$ : 0.06-0.55].

As the age of a child increased by one year, the presence of HIV-positive child decreased by $14 \%$ [AOR = 0.86, 95\% CI: $0.76-0.97$ ]. Those who said HIV testing is not important were more likely to have HIV-positive children than index participants who said HIV testing is important $[\mathrm{AOR}=5.20,95 \%$ CI: 2.2011 .96$]$.

Participants who did not discuss with family members about HIV testing had HIV-positive children more often than participants who had discussions with family members $[\mathrm{AOR}=3.22,95 \% \mathrm{CI}: 1.51-6.84]$ (Table 3 ).

\section{Discussion}

The findings show the HIV prevalence in children from family index cases was $8.9 \%$ [CI 6.5 -11.6]. Sex, age, 


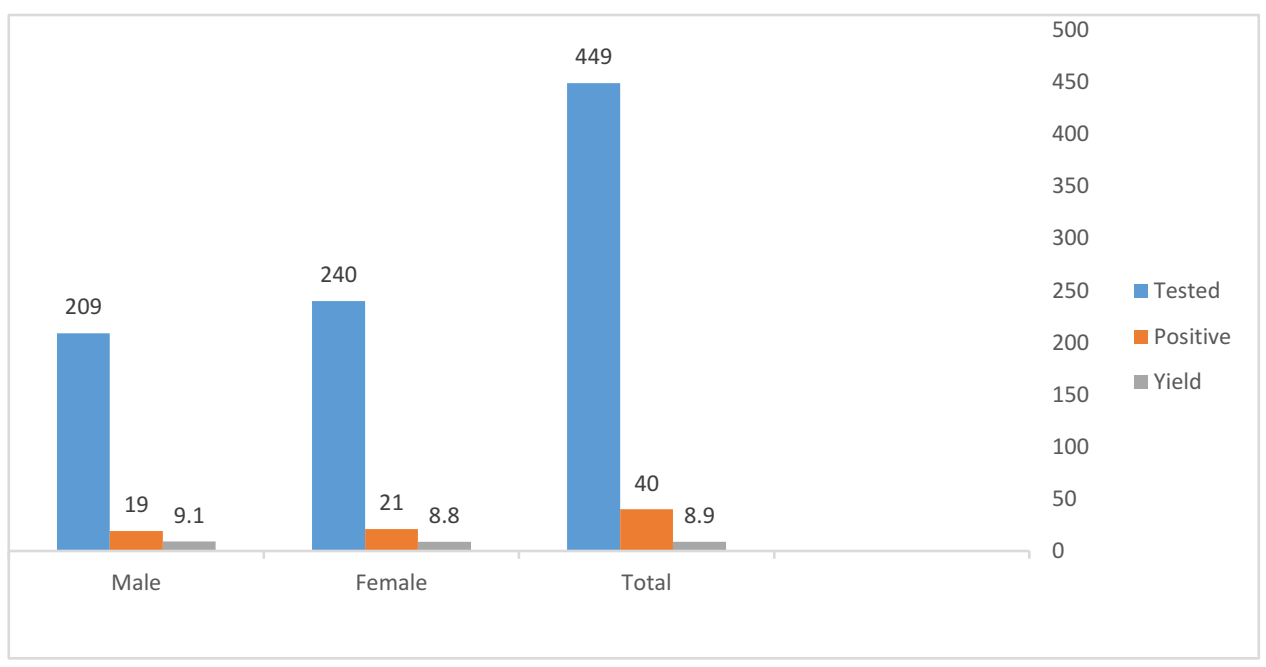

Figure 2 HIV status in children by sex from family index case testing at general Hospitals, central zone, Tigrai, Northern Ethiopia,20I9.

knowledge on the importance of HIV testing, and discussion about HIV testing of the adult index case had a significant association with the outcome variable.

The prevalence was higher than a study done by the Federal Democratic Republic of Ethiopia under the President's Emergency Plan For AIDS Relief (PEPFAR) Division of Global HIV/AIDS Center for Global Health which yielded $4.5 \%$ prevalence. ${ }^{18}$ Conversely, the prevalence of HIV in children in this study is less than what was reported in Kenya at $18 \%,{ }^{19}$ a study was done in Malawi at $12.5 \%,{ }^{20}$ and a study conducted in 23 sub-Saharan Africa $20 \% .{ }^{21}$ In this study, the lower prevalence may reflect time difference as more strategies have been introduced to decrease transmission of HIV from adult index to children like the Prevention of Mother-to-Child Transmission service.

The higher rate of HIV positive in children from index cases, in this study was associated with index clients being male and poor knowledge about HIV and its risk assessment, which is similar to a previous study conducted in rural Ethiopia. ${ }^{22}$ Nearly two-thirds of the study participants were female. It might be the proportion of females enrolled for HIV care is higher than males in central Tigrai due to maternal testing practices.

However, female index clients were less likely to have HIV-positive children within the family member than male index participants [AOR $=0.18,95 \%$ CI: $0.06-.55$ ], which means a child with HIV-positive mothers has $82 \%$ lower odds of developing HIV than a child with their fathers HIV-positive. This result may be due to the difference in partners' ART status, and children usually receive care from their mother. As the age of the child increases by one year, the presence of the HIV-positive child within the family decreases by $14.4 \%$ (AOR $=0.86$, [95\% CI $0.76-$ $0.97]$ ); similar to a result found in Kenya. ${ }^{23}$

This finding reflects a higher risk of HIV transmission in early life, due to different factors like breastfeeding (BF) and lack of compliance with PMTCT. ${ }^{24}$ There were findings from Uganda, which suggest that the length of time from diagnosis to ART initiation and clinical illness of adult index cases were associated with HIV serostatus in children. ${ }^{25}$

Our findings show there is no association between a regular or non-regular partnership and disclosure of one's status to their families. Additionally, our finding was contrary to that of a study in Nigeria. ${ }^{26}$

Family members who said HIV testing is not important were found to be 5.2 more likely HIV-positive children as compared to family members who said HIV testing is important $[\mathrm{AOR}=5.20,(95 \%$ CI $2.20-11.96)]$. This finding can be explained by those parents who know the importance of HIV testing were likely to take their child to a health institution for HIV testing.

Index clients who did not discuss HIV/AIDS in their adult family had a 3.22 higher risk of HIV positive children in their family than those who undertook discussions with the adult family members $[\mathrm{AOR}=3.22,(95 \% \mathrm{CI}$ 1.51-6.84)]. This finding may indicate that those who undertook discussion had increased knowledge about transmission of HIV from families to children and thereby prevented their children from the risk of HIV infection.

Some perceptions influence HIV prevalence in children. Furthermore, poor knowledge on the importance of 


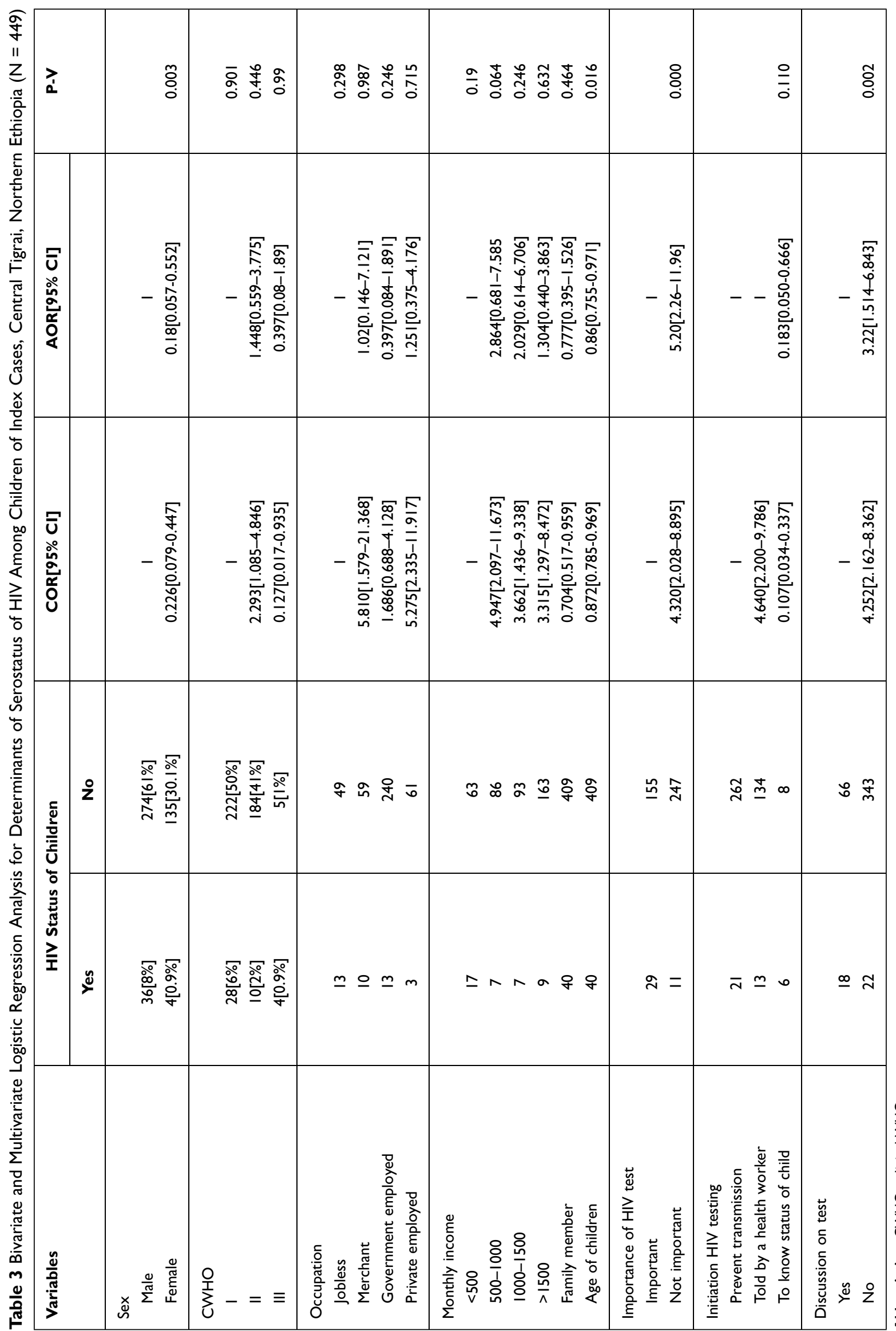


HIV testing, weak initiation of HIV testing for their children, and male participants were negatively influenced by the presence of an HIV-positive child in the family, the same association was also found in Nigeria. ${ }^{26}$

The limitation of the study was that it relied on selfreporting on certain elements, and therefore, it is subject to recall and reporting bias. The effect of social desirability bias is another limitation of this study. Additionally, all respondents of the study were HIV-positive index clients, who came for HIV care services to hospitals, which indicate some level of exposure and awareness on HIV transmission and outcome. Another weakness of this study is the limited sample size, because it may increase random error.

\section{Conclusion}

The majority of the index clients test their children, but the prevalence rate of HIV in the children from family index case testing remained high. Age of children, sex of index cases, and discussion with the family about HIV testing were the major factors for the presence of HIV-positive children in their family.

Pediatric testing from adult index case testing is a potentially high-yielding identification strategy. Despite this significant potential and failure to act upon the opportunity, the number of children infected with HIV remains unacceptably high.

\section{Data Sharing Statement}

Data will occur from the corresponding author through email.

\section{Ethical Considerations}

The study was conducted following the declaration of Helsinki on human subjects. After the purpose, benefit and risk was briefed, informed consent was obtained from the study participants. Ethical approval was obtained from the College of Health Sciences Research Ethics Review Committee (CHSREC) of Aksum University, and official permission was obtained from the Hospitals.

\section{Acknowledgments}

I would like to express my grateful appreciation to the organizations, especially to those ART clinic staff, who assisted in the completion of this project. Finally, I would like to thank ART clients who participated in this study.

\section{Funding}

The authors received no specific funding for this work.

\section{Disclosure}

The authors declare that they have no conflicts of interest regarding this work or the publication of this article.

\section{References}

1. Khongonyowa L, Schouten E, Aa. And Quality Improvement for Service Delivery January 2018 Strategy for Achieving HIV. Vol. I. 2016.

2. UNAIDS. To help end the AIDS epidemic. JC2684. 2014;1:1-40.

3. Save the Children. Family-Centered HIV Programming for Children; 2012.

4. PEPFAR. South Africa Country Operational Plan (COP) 2018 Strategic Direction Summary. 2018:50

5. Bekker L, Siberry GK, Hirnschall G. Ensuring children and adolescents are not left behind. J Acquir Immune Defic Syndr. 2018;78 (1):1-2. doi:10.1097/QAI.0000000000001751

6. Filteau S. The HIV-exposed, uninfected African child. Trop Med Int Heal. 2009;14(3):276-287. doi:10.1111/j.1365-3156.200 9.02220.x

7. Belayneh TW. Assessment of Tracing Family Members of HIV Positive People for HIV Testing and Associated Factors among ART Clinic Attendants at Felege Hiwot Referral Hospital, Northwest Ethiopia. 2017;15:16-28.

8. Federal Ministry of, Health. National Guidelines for Comprehensive HIV Prevention, Care and Treatment. 2017:1226.

9. UNAIDS. On the Right Track Towards the Global Target. Vol. II; 2016:21

10. Academy A, Pediatrics OF, Care F. Committee on Hospital Care. 2003;112:3.

11. Betancourt TS, Abrams EJ, McBain R, Fawzi MC. Family-centred approaches to the prevention of mother-to-child transmission of HIV. J Int AIDS Soc. 2010;13(SUPPL.2).

12. USAID. Partner and Family-Based Index Case Testing: A Standard Operating Procedure (SOP).

13. WH0, Pepfar U. Partner and Family-Based Index Case Testing. 2015; $1: 42$.

14. WHO. A Practical Handbook for Sub-Saharan Africa. Vol. 4. 2012:34-36

15. Sidibé M. UNAIDS data 2018. 2018;1:10-32.

16. UNAIDS) JUNP on H. Start Free Stay Free AIDS Free 2017 Progress Report. 2017:1-84

17. CDC. Strategies for Identifying and Linking HIV-Infected Infants, Children, and Adolescents to HIV Care and Treatment. 2015:4-8

18. Announcement FO, Hiv G, Centers GH, Control D Increasing Access TO HIV Counseling and Testing Services for High-Risk Populations, and Improving Linkage, Engagement, and Retention in Care and Support Services in the Federal Democratic Republic of Ethiopia under the President's Emergency Plan for AI. 2014.;

19. Lewis Kulzer J, Penner JA, Marima R, et al. Family model of HIV care and treatment: a retrospective study in Kenya. J Int AIDS Soc. 2012;15(1):1-6. doi:10.1186/1758-2652-15-8

20. Ahmed S, Sabelli RA, Simon K, et al. Index case finding facilitates identification and linkage to care of children and young persons living with HIV/AIDS in Malawi. Trop Med Int Heal. 2017;22 (8):1021-1029. doi:10.1111/tmi.12900

21. Short SE, Goldberg RE. Children Living with HIV-Infected Adults: Estimates for 23 Countries in Sub-Saharan Africa. 2015: $1-17$. 
22. Teklehaimanot HD, Teklehaimanot A, Yohannes M, Biratu D. Factors influencing the uptake of voluntary HIV counseling and testing in rural Ethiopia: a cross-sectional study. BMC Public Health. 2016;16 (1):1-13

23. Shukla M, Agarwal M, Singh J, Tripathi A, Srivastava A, Singh V. Evaluation and Utility of a Family Information Table to Identify and Test Children at Risk for HIV in Kenya. Indian J Community Med. 2016;41(1):55. doi:10.4103/0970-0218.170970

24. Essajee S, Putta N, Brusamento S, Penazzato M, Mark D. Family-Based Index Case Testing to Identify Children with HIV. 2017:1-4.
25. Kahungu MM, Kiwanuka J, Kaharuza F, Wanyenze RK. Factors associated with HIV positive sero-status among exposed infants attending care at health facilities: a cross-sectional study in rural Uganda. BMC Public Health. 2018;18(1):1-11. doi:10.1186/s12889018-5024-6

26. Iwelunmor J, Ezeanolue EE, Airhihenbuwa CO, Obiefune MC, Ezeanolue CO Socio-cultural factors influencing the prevention of mother-to-child transmission of HIV in Nigeria: a synthesis of the literature. 2014;1-13.

HIV/AIDS - Research and Palliative Care

\section{Publish your work in this journal}

HIV/AIDS - Research and Palliative Care is an international, peerreviewed open-access journal focusing on advances in research in HIV, its clinical progression and management options including antiviral treatment, palliative care and public healthcare policies to control viral spread. The manuscript management system is completely online and includes a very quick and fair peer-review system, which is all easy to use. Visit http://www.dovepress.com/testimonials.php to read real quotes from published authors. 